\title{
Seed priming with sodium nitroprusside attenuates the effects of water deficit on soybean seedlings
}

\author{
Marina Alves Gavassi', Lucas Aparecido Gaion², Carolina Cristina Monteiro², \\ Joel Cabral Santos², Rogério Falleiros Carvalho ${ }^{*}$
}

'São Paulo State University, Rio Claro, Brazil

${ }^{2}$ São Paulo State University, Jaboticabal, Brazil

*Corresponding author, email: rogerio.f.carvalho@unesp.br

\begin{abstract}
Considering that water deficit is one of the main environmental factors responsible for low soybean yield and that nitric oxide ( $\mathrm{NO}$ ) has been shown to be a fundamental part of plant defense signaling during stress, the aim of the present study was to evaluate the effect of seed priming with nitric oxide on the induction of water deficit tolerance during the initial development of soybean. Thus, seeds were treated with 0 (water only), 50, 100 or $250 \mu \mathrm{mol}^{. \mathrm{L}^{-1}}$ sodium nitroprusside for 6 hours. Additionally, untreated seeds were used. After drying, the seeds were placed in containers filled with a commercial substrate mixture and vermiculite and irrigated to $100 \%$ and $50 \%$ field capacity. Biometric and biochemical evaluations (pigment and proline contents) were performed after 14 days. It was concluded that pretreatment of soybean seeds with 50 to $250 \mu \mathrm{mol} . \mathrm{L}^{-1}$ SNP attenuated the effects of water deficit on stem growth, leaf area, and shoot dry matter and induced carotenoid biosynthesis. The accumulation of proline in the leaves was pronounced in the treatments with 100 and $250 \mu \mathrm{mol} . \mathrm{L}^{-1} \mathrm{SNP}$, while $100 \mathrm{\mu mol} \mathrm{LL}^{-1}$ SNP induced proline accumulation in the roots.
\end{abstract}

Keywords: : Glycine max, germination, water deficit

\section{Introduction}

Brazil ranks second in world soybean production (Glycine max L.) (EMBRAPA, 2018), and each year, increases are recorded both in the planted area and quantity produced. However, recurrent environmental factors in these areas, such as water deficit, may negatively affect germination, growth and crop development, causing yield losses and low-quality seeds (Furlan et al., 2012).

Biochemical methods, such as seed priming (SP), have been efficient strategies to induce tolerance to water deficit. This technique consists of imbibing seeds into natural or synthetic compounds for a determined period of time, suspending imbibition after the induction of germination but without allowing germination to complete, that is, before root protrusion (Jisha et al., 2013, Ibrahim, 2016). This practice allows the embryo to store biochemical information that will enable it to cope with subsequent stress conditions (Prom-u-thai et al., 2012).

Although SP in soybean is not commercially used on a large scale, several studies have shown its results in improving the physiological quality of seeds and seedlings (Arifet et al., 2010, Kering \& Zhang 2015; Silva et al., 2016). Among the solutions used in imbibition, SP with polyethylene glycol (PEG) (Sun et al., 2010), hormones (Mahmoudi et al., 2012; Sneideris et 
al., 2015), salts and metals (Prom-u-thai et al. al., 2012) has efficiently induced tolerance to water deficit. There is evidence that the molecules of the oxidative system act as signals and induce antioxidant agents in the seed, which can be activated in the seedling and help protect against damage caused by oxidation. Nitric oxide (NO), for example, is a reactive nitrogen species belonging to the oxidative system that, depending on the concentration, acts as a signaling molecule or free radical (Corpas \& Barroso 2015; Jiao et al., 2016; Sadeghipour, 2016). Both reactive oxygen species (ROS), hydrogen peroxide $\left(\mathrm{H}_{2} \mathrm{O}_{2}\right)$, and reactive nitrogen species (RNS), such as NO, are involved in a number of stress responses, such as temperature extremes and water deficit (Hancock et al., 2011). Preexposure to a molecule of the oxidative system, such as NO, can lead to a "memory of stress", and this effect is responsible for the crosstolerance observed in some studies (Bruce et al., 2007; Wahid et al., 2007).

In recent years, it has become clear that NO has a key role in plant defense signaling under stress conditions, such as high salinity (Zanotti et al., 2013), UV-B radiation (Gupta et al., 2011) and, especially, water deficit (Cho et al., 2013). In addition, the exogenous application of NO releasers resulted in increased seed germination rates and seedling initial growth under several adverse conditions (Zheng et al., 2009; singh et al., 2013; Egbichi et al., 2014). Among the various NO-generating compounds, sodium nitroprusside is one of the most used in studies on plant signaling due to its efficiency, especially in leaf tissues (Ederli et al., 2009).

Thus, it is relevant to hypothesize that the use of NO releasers during seed priming may be an important strategy to induce tolerance during the early development of soybean grown under water deficit.

\section{Material and methods}

Plant material and pretreatment

The soybean seeds used belong to the cultivar M7211-RR. For priming, the seeds were placed in transparent plastic boxes (11) $11 \times 3.5$ $\mathrm{cm}$ ) containing two sheets of germbox paper embedded in $15 \mathrm{~mL}$ of $0,50,100$ or $250 \mu \mathrm{mol}^{. \mathrm{L}^{-1}}$ sodium nitroprusside solution (SNP), a NO releaser, for 6 hours. After pretreatment, the seeds were dried at $25^{\circ} \mathrm{C}$ for 48 hours. As a control, soybean seeds were used without any pretreatment (NT).

\section{Growth analysis}

The seeds were placed in plastic containers of $400 \mathrm{~mL}, 1$ seed per container, filled with a commercial substrate mixture and vermiculite $(3: 1 \mathrm{v} / \mathrm{v})$, which received treatment equivalent to field capacity (FC) and $50 \%$ of FC. For maintenance of the treatments, the transpiration of each plant was evaluated daily through the difference in the weight of the pots in a time interval of two hours (9:00 a.m. to 11:00 a.m.) using a precision scientific scale (Analytical balance - Mars, AS2000C, Brazil). To calculate transpiration, the surface and base of the pot were covered temporarily with adhesive tape to minimize evaporation (Puértolas et al., 2015). The calculations for the replacement were based on the evaporation from the pots filled with the commercial substrate and vermiculite (3:1), without plants and irrigated with both water regimes, plus the transpiration of each plant. The experiment was conducted in a controlled environment with $360 \mu \mathrm{mol} . \mathrm{m}^{-2} . \mathrm{s}^{-1}$ irradiance and a 14-hour photoperiod at $25^{\circ} \mathrm{C}$.

The experiment was carried out for 14 days, and the analyses described below were performed at the end of the experiment. Shoot and root growth measurements were performed using a graduated ruler $(\mathrm{cm})$. Later, the organs were packed separately in craft paper bags and submitted to forced air drying at $60{ }^{\circ} \mathrm{C}$. Leaf area was measured with an automatic leaf area integrator (LI3000A, Li-COR, Lincoln-NE, Brazil). Dry weight was measured by a precisionbased scientific scale (Analytical Balance - Mars, AS2000C, Brazil) USA).

To determine the area, diameter, density and total root length, a Delta-T Scan (Delta-T Devices LTD analysis system, England) was used. For this, the root system remained in methylene blue solution for approximately 2 minutes. The roots were then placed in a tray with distilled water to begin the image readings using a Hewlett Packard Model 5C digitizer. To obtain 
the data, the image of each root system was analyzed by Delta-T Scan software (Costa et al., 2014).

\section{Content of chlorophyll and carotenoids}

To evaluate the content of total leaf chlorophylls and carotenoids, two leaf discs (7.8 $\mathrm{mm}$ ) were removed with a punch from the first pair of fully expanded leaves, added to $1.5 \mathrm{~mL}$ of methanol and placed inside microtubes covered with aluminum paper. The extraction process was performed in triplicate. Subsequently, in dark conditions, the tubes remained for 24 hours under $4{ }^{\circ} \mathrm{C}$ while shaking. After shaking, the foliar tissues were removed, and the extraction solution containing the pigments was taken for reading at the following wavelengths: chlorophyll a -662 $\mathrm{nm}$; chlorophyll b - $645 \mathrm{~nm}$ and carotenoids (carotene $[c]+$ xanthophylls $[x]$ ) $-470 \mathrm{~nm}$. For the calculation of chlorophyll and carotenoid concentrations, the following formulas were used (Lichtenthaler, 1987):

$$
\begin{gathered}
C a=11.24 * \mathrm{~A} 662-2.04 * \mathrm{~A} 645 ; \\
\mathrm{Cb}=20.13 * \mathrm{~A} 645-4.19 * \mathrm{~A} 662 \\
\mathrm{Ca}+\mathrm{b}=7.05 * \mathrm{~A} 662+18.09 * \mathrm{~A} 645 \\
\mathrm{C} c+\mathrm{x}=(1000 * \mathrm{~A} 470-1.90 * \mathrm{Ca}-63.14 * \mathrm{Cb}) / \\
214 .
\end{gathered}
$$

The chlorophyll and carotenoid contents of the tissues were expressed in micrograms of pigment per leaf disc area $\left(\mu \mathrm{g} . \mathrm{cm}^{-2}\right)$.

\section{Proline content}

The proline (PRO) content in the leaves and roots was obtained according to Bates et al. (1973). The extraction was carried out from $500 \mathrm{mg}$ of plant material (leaves and roots) homogenized with $5 \mathrm{~mL}$ of $3 \%$ sulfosalicylic acid. After that, two filtrations were carried out, and a 1 $\mathrm{mL}$ aliquot of proline was taken for quantification. The reaction was started by adding $1 \mathrm{~mL}$ of acidic ninhydrin and $1 \mathrm{~mL}$ of $99.5 \%$ glacial acetic acid to the sample. The mixture was shaken and incubated at $100^{\circ} \mathrm{C}$ for 60 minutes. The samples were cooled on ice, and $2 \mathrm{ml}$ of tolvene was added for the separation phase. The fraction containing the chromophore group was collected, and the absorbance was determined at $520 \mathrm{~nm}$ in a spectrophotometer (Beckman DU 640). The proline concentration was determined by a proline calibration curve, and the result is expressed in micromoles of proline per gram of fresh weight (FW).

\section{Statistical analysis}

The experiment was carried out in a completely randomized experimental design with 5 replicates. Analysis of variance (ANOVA) was used to compare treatments, and significant differences between means were determined by the Scott-Knott test $(p<0.05)$.

\section{Results and discussion}

The stem growth (SG) and leaf area (LA) of the soybean seedlings in the water deficit condition were considerably higher in the treatments with 50, 100 and $250 \mu$ mol.L-1 SNP compared with the NT and water only treatments (Figure 1). In addition, the SG and LA values observed under stress conditions in all SNP treatments were similar to those of the control condition (Figure $1 \mathrm{~A}$ and $\mathrm{B}$ ). These results suggest that the release of $\mathrm{NO}$ can attenuate the effect of water deficit on the development of the leaf area, also evidenced by the shoot dry weight (SDW), in which concentrations of 50 and 250 $\mu$ mol.L-1- SNP promoted an increase in the SDW in the stress condition when compared to the NT (Figure 1C).

The wheat seedlings pretreated with SNP showed minimal deleterious effects of high salinity in leaf area and dry weight (Wahid et al., 2007). On the other hand, although the SNP increased the germination rate of Suaeda salsa under high salinity, there was no change in the seedling growth under stress compared to that in the control condition (Song et al., 2009). During stress induced by the presence of cadmium, SNP added to the treatment partially inhibited the damage caused by the heavy metal on the growth and dry weight of both the stem and the radicle in sesame (Pires et al., 2016).

The accumulation of NO-induced chlorophyll was observed in canola and tomato under cadmium-induced stress (Zhang et al., 2010; Jhanji et al., 2012), wheat under high temperature (Hasanuzzaman et al., 2012), pumpkin under low temperatures and waterlogging (Liv et al., 2011; Fan et al., 2014), and turfgrass with a water 
deficit (Hatamzadeh et al., 2015). However, in the present work, there was no change in the chlorophyll content among the treatments with SNP under the established conditions (Figure 2A). It is possible that the attenuation of the harmful effects of water deficit on the growth of seedlings
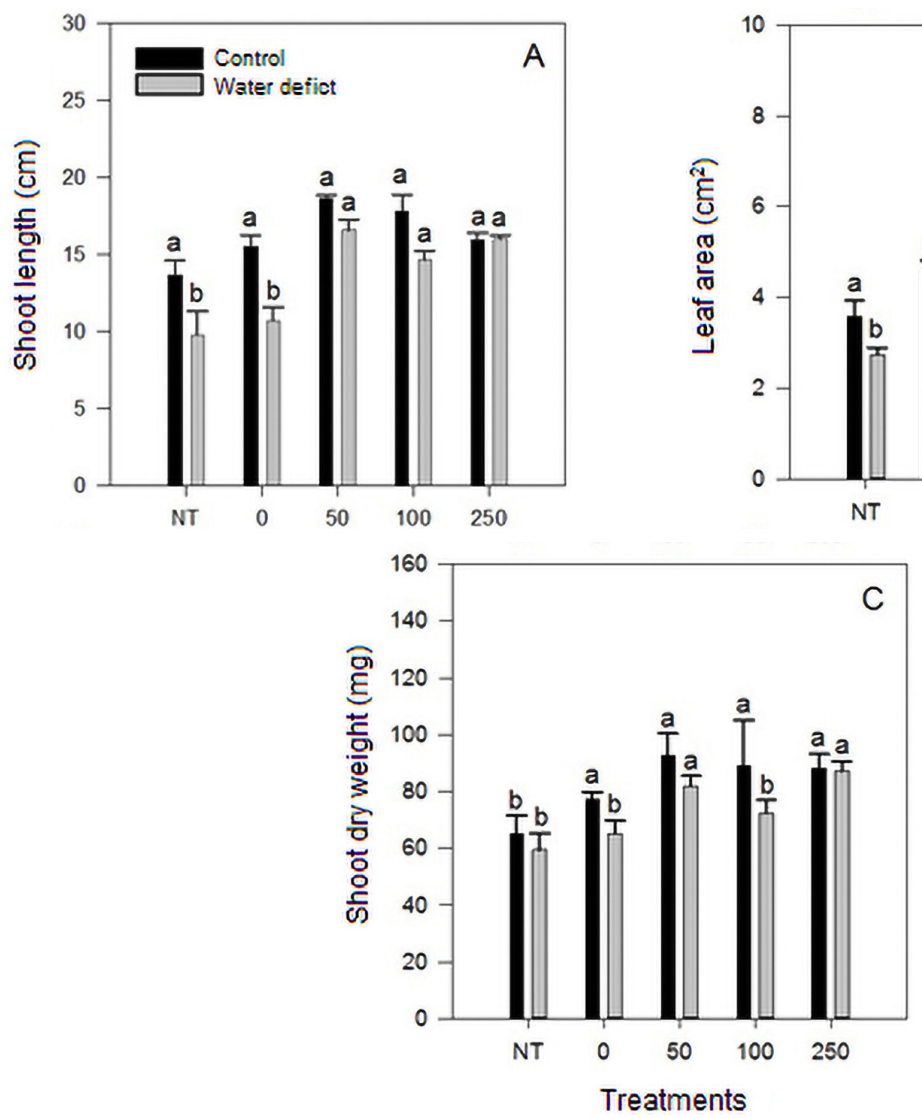

Figure 1. Shoot length (A), leaf area (B) and shoot dry weight (C) of soybean seedlings from pretreated seeds with 0, 50, 100 and $250 \mu$ mol.L-1 sodium nitroprusside for 6 hours and the untreated seeds (NT) at 14 days under field capacity (FC) and 50\% FC water availability. Means followed by the same letter did not differ by the Scott-Knott test ( $p<0.05)$.
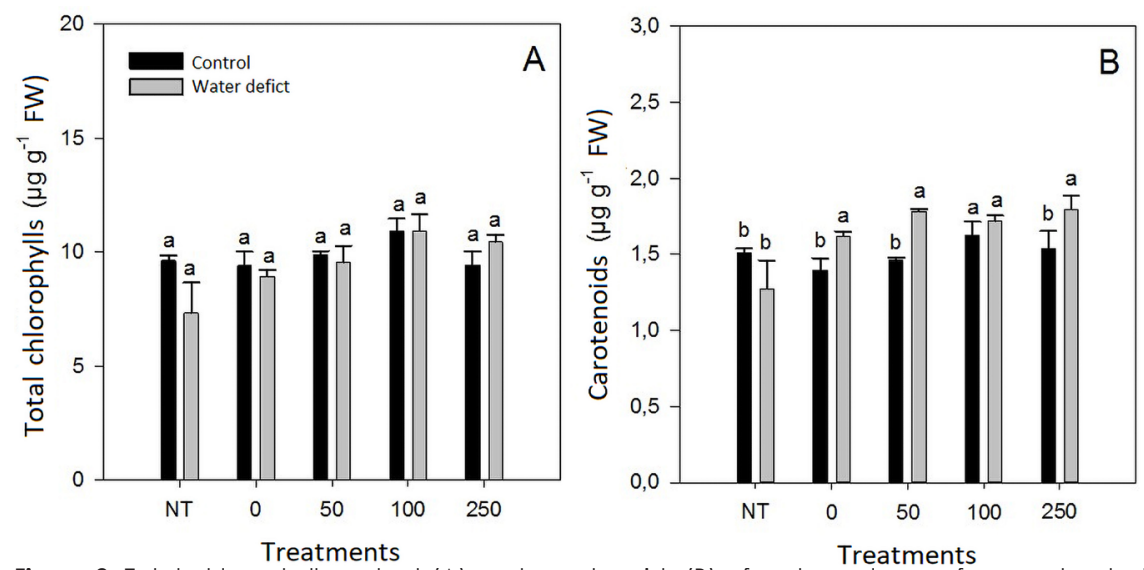

Figure 2. Total chlorophyll content (A) and carotenoids (B) of soybean leaves from pretreated seeds with $0,50,100$ and $250 \mu \mathrm{mol} . \mathrm{L}^{-1}$ sodium nitroprusside for 6 hours and untreated seeds (NT) at 14 days under field capacity (FC) and 50\% FC water availability. Means followed by the same letter did not differ by the Scott-Knott test ( $p<0.05)$. 
Carotenoids, in addition to being accessory pigments of the photosynthetic apparatus, are also considered as part of the nonenzymatic mechanism of stress responses because they are lipophilic antioxidants and capable of detoxifying various forms of ROS (Havaux, 2013). The treatment with only water and all treatments with SNP promoted an increase in the carotenoid content in the water deficit condition. Among them, treatment with 100 umol.L-1 SNP increased the carotenoid content in the leaves in both conditions compared to that in NT (Figure 2B). Thus, it is also possible that carotenoids have attenuated the effect of ROS under the photosynthetic apparatus and, consequently, on chlorophyll molecules (Sharma et al., 2012).

In addition to carotenoids, proline is also considered as part of the nonenzymatic mechanism of stress response. Because it is responsible for osmotic adjustment and the maintenance of cellular turgor, PRO is one of the most commonly compatible osmolytes found during water deficit (Mafakheri et al., 2010). Its importance is also due to its role in redox signaling and the effective suppression of ROS formation in plants under high salinity, heavy metal contamination, water deficit and other

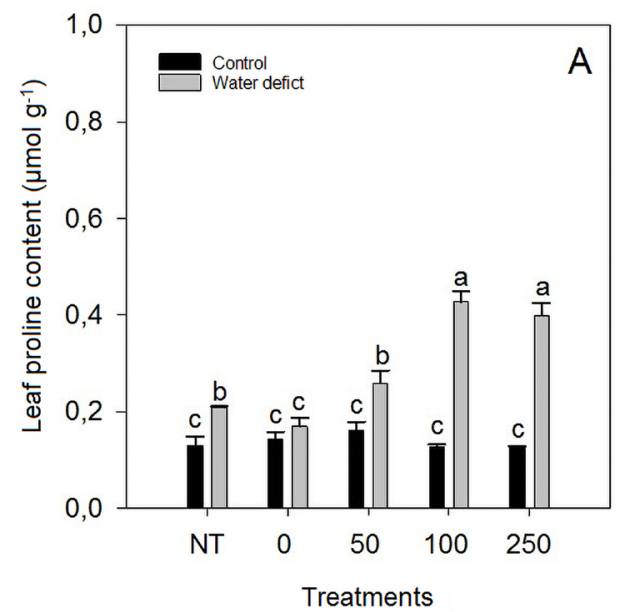

Figure 3. Chlorophyll content in leaves (A) and roots (B) of soybean seedlings from pretreated seeds with $0,50,100$ and $250 \mu \mathrm{mol} . \mathrm{L}^{-1}$ sodium nitroprusside for 6 hours and untreated seeds (NT) at 14 days under field capacity (FC) and 50\% FC water availability. Means followed by the same letter did not differ by the Scott-Knott test $(p<0.05)$

Some studies have shown the effects of NO donors in root growth induction and formation, including adventitious roots (Pagnussat et al., 2002; Correa-Aragunde et al., 2004). In the present study, the effect of NO on root growth

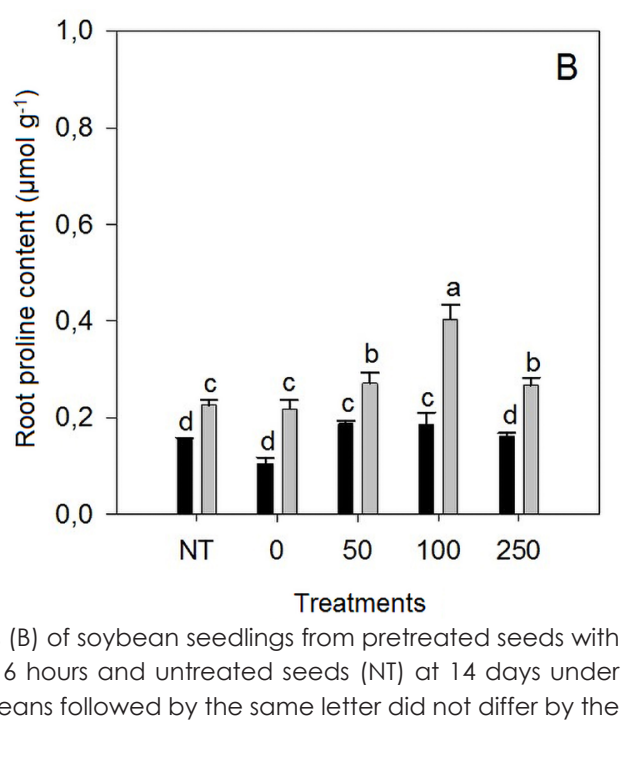

stresses (Gill \& Tuteja, 2010).

In this context, knowing that $\mathrm{NO}$ is responsible for the activation of some key enzymes in PRO synthesis (Zhang et al., 2008), the accumulation of PRO was observed under water deficit in the leaves of the seedlings treated with 100 and $250 \mu \mathrm{mol} . \mathrm{L}^{-1}$ SNP when compared to those of NT, which did not occur in the control condition (Figure 3A). In the roots, all treatments with SNP provided an increase in the PRO content under water deficit, especially the treatment with $100 \mu \mathrm{mol} . \mathrm{L}^{-1}$ SNP. It was also verified that the treatments with 50 and 100 umol.L-1 SNP accumulated PRO in the control condition when compared with NT (Figure 3B). These results indicate that soybean seed priming

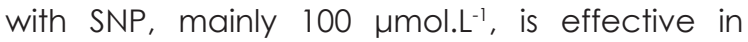
inducing PRO biosynthesis in seedlings under water deficit conditions, which probably occurs by the induction of key enzymes still in the embryo. Some studies have found similar results on the positive effects of SNP application on proline accumulation and stress attenuation in wheat under high salinity (Kausar et al., 2013), wheat under arsenic-induced oxidative stress (Hasanuzzaman \& Fujita, 2013) and cotton under water deficit (Shallan et al., 2012).

was verified through the main root length (MRL) (Figure 4A), total root length (TRL) (Figure 4B), root diameter (RDi) (Figure $4 C$ ), root density (RDe) (Figure 4D), root area (RA) (Figure 4E) and root dry weight (RDW) (Figure 4F). 

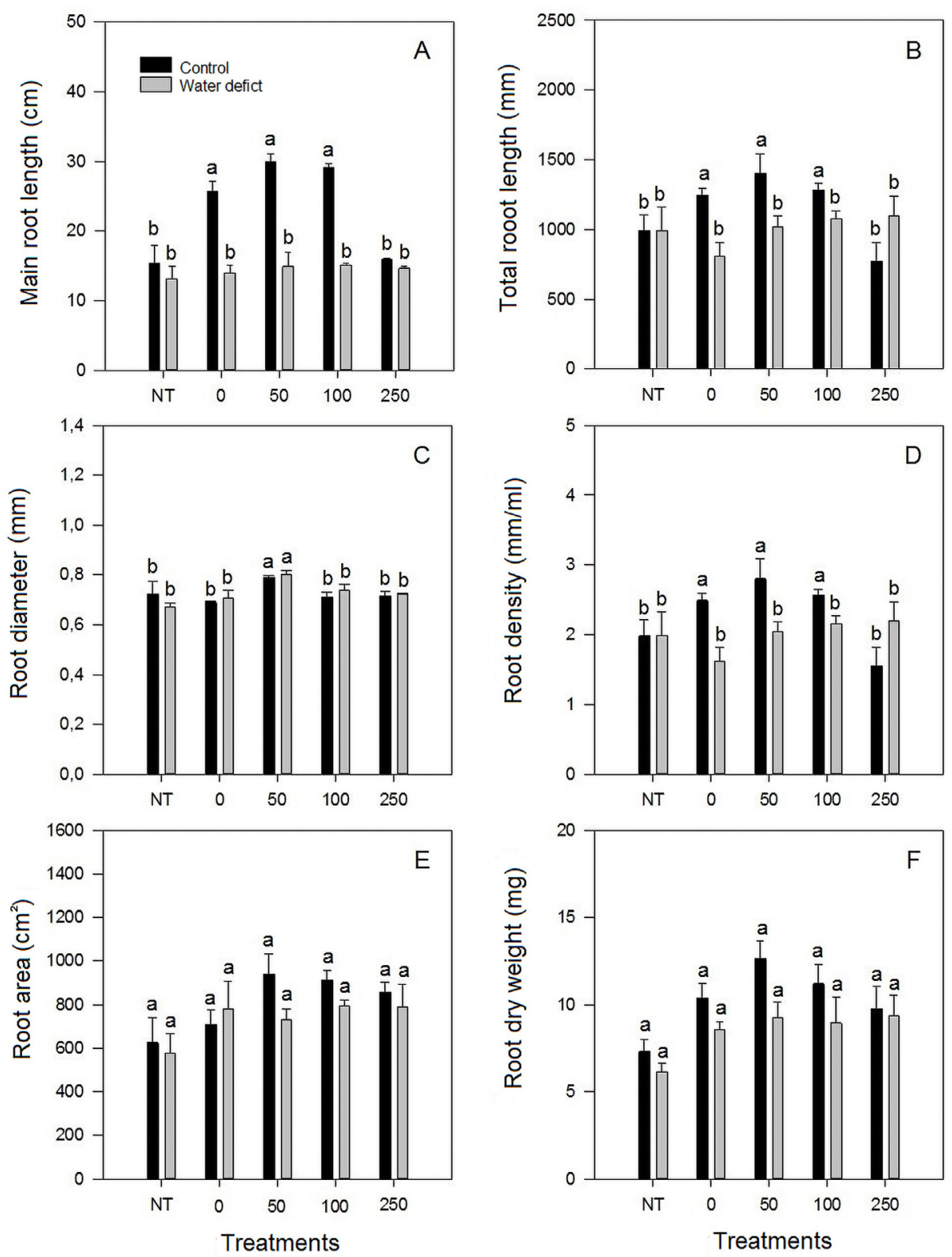

Figure 4. Main root length (A), total root length (B), root diameter (C), root density (D), root area (E) and root dry weight (F) of soybean seedlings from pretreated seeds with $0,50,100$ and $250 \mu \mathrm{mol} . \mathrm{L}^{-1}$ sodium nitroprusside for 6 hours and untreated seeds (NT) at 14 days under field capacity (FC) and $50 \%$ FC water availability. Means followed by the same letter did not differ by the Scott-Knott test ( $p<0.05)$.

In addition to the abovementioned effects of NO, the benefits of SNP in the accumulation of $\mathrm{PRO}$ in roots were expected to provide better growth under water deficit.

However, there was a difference between the treatments only for the RDi, with the highest value of this variable observed in the treatment with $50 \mu$ mol.L-1 SNP, both in the control condition and under water deficit (Figure 4C). Although no significant NO-induced differences were observed in the root variables evaluated under water deficit, it is important to note that in the control condition, water treatment, 50
mol.L-1 $^{-1}$ SNP and $100 \mu \mathrm{mol} . \mathrm{L}^{-1}$ SNP provided, respectively, an increase of $50.5 \%, 75.2 \%$ and $70.6 \%$ in MRL compared with NT (Figure 4A). Under the same conditions, in addition to MRL, the same treatments caused an increase in TRL (25.7\%, $41.3 \%$ and $29.4 \%$, respectively) and RDe (25.8\%, $41.4 \%$ and $29.8 \%$, respectively) (Figure $4 B$ and $D)$, indicating the beneficial role of pretreatment in root growth.

Although the effects of $\mathrm{NO}$ on root development have not been evident in this study, a large number of studies have verified the involvement of this RNS in root development 
and gravitropic responses (Wen et al., 2016). For example, Wen et al. (2016) demonstrated that in tomato plants, auxin promotes the development of adventitious roots through the accumulation of NO, which, in turn, induces the expression of the genes responsible for the formation of adventitious roots. In addition, cucumber plants under water deficit exhibit higher NO production in the area of root elongation (ArasimowiczJeloneket al., 2009). Thus, these authors observed that plants treated with an NO synthase inhibitor exhibited lower relative water content and increased oxidative stress under water deficit conditions, indicating an important role of $\mathrm{NO}$ in drought tolerance.

\section{Conclusions}

Soybean seed priming with 50 to 250 $\mu$ mol.L-1 SNP attenuated the effects of water deficit on stem growth, leaf area, and shoot dry weight and induced carotenoid biosynthesis. The accumulation of proline in the leaves was evidenced in the treatments with 100 and 250 umol.L-1 SNP, while $100 \mu \mathrm{mol} . \mathrm{L}^{-1}$ SNP induced proline accumulation in the roots.

\section{References}

Arasimowicz-Jelonek, M., Floryszak-Wieczorek, J., Kubis J. 2009. Involvement of nitric oxide in water stress-induced responses of cucumber roots. Plant Science 177(6): 682-690.

Bates, L.S., Waldren, R.P., Teare, I.D. 2013. Rapid determination of free proline for water-stress studies. Plant and Soil 39(1): 205-207.

Bruce, T.J.A., Matthes, M.C., Napier, J.A Pickett, J.A. 2007 Stressful memories of plants: evidence and possible mechanisms. Plant Science 173(6): 603-608.

Cho, S., Kim, Y.H., Anderson, A.J. 2013. Nitric oxide and hydrogen peroxide production are involved in systemic drought tolerance induced by $2 R, 3 R$-butanediol in Arabdopsis thaliana. Plant Pathology Journal 29(4): 427-434.

Corpas, F.J., Barroso, J.B. Functions of nitric oxide (NO) in roots during development and under adverse stress conditions. Plants 4: 240-252.

Correa-Aragunde, N., Graziano, M., Lamattina, L. 2004. Nitric oxide plays a central role in determining lateral root development in tomato. Planta 218(6): 900-905.

Egbichi, I., Keyster, M., Ludidi, N. 2014. Effect of exogenous application of nitric oxide on salt stress responses of soybean. South African Journal of Botany 90: 131-136.

Empresa Brasileira de Pesquisa Agropecuária Embrapa. 2018. https://www.embrapa.br/soja/ cultivos/sojal/dados-economicos <Accessed: 10 Sep. 2018>

Fan, H.F., Du, C.X., Ding, L., Xu, Y.L. 2014. Exogenous nitric oxide promotes waterlogging tolerance as related to the activities of antioxidant enzymes in cucumber seedlings. Russian Journal of Plant Physiology 61 (3): 366-373.

Furlan, A., Llanes, A., Luna, V., Castro, S. 2012. Physiological and biochemical responses to drought stress and subsequent rehydration in the symbiotic association peanut - Bradyrhizobium sp. Agronomy n. 2012:318083.

Gill, S.S., Tuteja, N. 2010. Reactive oxygen species and antioxidant machinery in abiotic stress tolerance in crop plants. Plant Physiology and Biochemestry 48: 909-930.

Hasanuzzaman, M., Nahar, K., Alam, M., Fujita, M. 2012. Exogenous nitric oxide alleviates high temperature induced oxidative stress in wheat (Triticum aestivum L.) seedlings by modulating the antioxidant defense and glyoxalase system. Australian Journal of Crop Science 6(8): 13141323.

Hasanuzzaman, M., Fujita, M. 2013. Exogenous sodium nitroprusside alleviates arsenic-induced oxidative stress in wheat (Triticum aestivum L.) seedlings by enhancing antioxidant defense and glyoxalase system. Ecotoxicollogy 22(3): 584-596.

Hatamzadeh, A, Nalousi, M., Ghasemnezhad, M., Biglovei, M.H. 2015. The potential of nitric oxide for reducing oxidative damage induced by drought stress in two turfgrass species, creeping bentgrass and tall fescue. Grass and Forage Science 70(3): 538-548.

Ibrahim, E. A. 2016. Seed priming to alleviate salinity stress in germinating seeds. Journal of Plant Physiology 192: 38-46.

Jhanji, S., Setia, R.C., Kaur, N., Kaur, P., Setia, N. 2012. Role of nitric oxide in cadmium-induced stress on growth, photosynthetic components and yield of Brassica napus L. Journal of Environmental Biology 33(6): 1027-1032.

Jiao, C., Yang, R., Zhou, Y., Gu, Z. 2016. Nitric oxide mediates isoflavone accumulation and the antioxidant system enhancement in soybean sprouts. Food Chemistry 204: 373-380.

Jisha, K.C., Vijayakumari, K., Puthur, J.T. 2013. Seed priming for abiotic stress tolerance: an overview. Acta Physiologiae Plantarum 35: 1381-1396. 
Kausar, F., Shahbaz, M, Ashraf, M. 2013. Protective role of foliar-applied nitric oxide in Triticum aestivum under saline stress. Turkish Journal of Botany 37: 1155-1165.

Kering, M.K., Zhang, B. 2015. Effect of priming and seed size on germination and emergence of six food-type soybean varieties. International Journal of Agronomy n. 859212.

Lichtenthaler, H. K. 1987. Chlorophylls and carotenoids: pigments of photosynthetic biomembranes. Methods in Enzymology 148: 350 382.

Liu, X., Wang, L., Liu, L., Gou, Y., Ren, H. 2011. Alleviating effect of exogenous nitric oxide in cucumber seedling against chilling stress. African Journal of Biotechnology 10(21): 4380-4386, 2011.

Mahmoudi, H., Massoud, R.B., Baatour, O., Tarchoune, I., Salah, I.B., Nasri, N., Abidi, W., Kaddour, R., Hannoufa, A., Lachaâl, M., Ouergui, Z. 2012. Influence of different seed priming methods for improving salt stress tolerance in lettuce plants. Journal of Plant Nutrition 35(12): 1910-1922.

Mafakheri, A., Siosermardeh, A., Bahramnejad, B., Struik, P.C., Sohrabi, Y. 2010. Effect of drought stress on yield, proline and chlorophyll contents in three chickpea cultivars. Australian Journal Crop Science 4(8): 580-585.

Pagnussat, G.C., Simontacchi, M., Puntarulo, S., Lamattina, L. 2002. Nitric oxide is required for root organogenesis. Plant Physiology129(3): 954-956.

Pires, R.M.O. 2016. Action of nitric oxide in sesame seeds (SesamumindicumL.) submitted to stress by cadmium. Journal of Seed Science 38(1): 022029.

Prom-U-Tay, C., Rerkarsem, B., Yazici, A., Cakmak, I. 2012. Zinc priming promotes seed germination and seedling vigor of rice. Journal of Plant Nutrition and Soil Science 175: 482-488.

Sadeghipour, O. 2016. Pretreatment with nitric oxide reduces lead toxicity in cowpea (Vigna unguiculata [L.] Walp.). Archieves of Biological Sciences Belgrade 68(1): 165-175.

Shallan, M.A., Hassan, H.M.M., Namich, A.A.M., Ibrahim, A.A. 2012. A Effect of sodium nitroprusside, putrescine and glycine betaine on alleviation of drought stress in cotton plant. American-Eurasian Journal of Agriculture \& Environment Science 12(9): 1252-1265.

Sharma, P., Jha, A.B., Dubey, R.S., Pessarakli, M. 2012. Reactive oxygen species, oxidative damage, and antioxidative defense mechanism in plants under stressful conditions. Journal of Botany n. 217037.
Silva, T.A., Silva, P.B., Silva, E.A.A., Nakagawa, J., Cavariani, C. 2016 Condicionamento fisiológico de sementes de soja, componentes de produção e produtividade. Ciência Rural 46(2): 227-232.

Singh, V.P., Srivastava, P.K., Prasad, S.M. 2013. Nitric oxide alleviates arsenic-induced toxic effects in ridged Luffa seedlings. Plant Physiology and Biochemistry 71: 155-163.

Sneideris, L.C., Gavassi, M.A., Campos, M.L., C'Amico-Damião, V., Carvalho, R.F. 2015. Effects of hormonal priming on seed germination of pigeon pea under cadmium stress. Anais da Academia Brasileira de Ciências 87(3): 18471852.

Song, J., Xing, S., Chen, Min, Wang, B., 2009. Effects of nitric oxide and nitrogen on seedling emergence, íon accumulation, and seedling growth under salinity in the euhalophyte Suaeda salsa. Journal of Plant Nutrition and Soil Science 172: 544-549.

Sun, Y., Sun, Y.J., Wang, M.T., Li, X.Y., Guo, X., $\mathrm{Hu}$, R., Ma, j. 2010. Effects of seed priming on germination and seedling growth under water stress in rice. Acta Agronomica Sinica 36(11): 1931-1940.

Wahid, A., Perveen, M., Gelani, S., Basra, S.M. 2007. Pretreatment of seed with $\mathrm{H}_{2} \mathrm{O}_{2}$ improves salt tolerance of wheat seedlings by alleviation of oxidative damage and expression of stress proteins. Journal of Plant Physiology 164: 283-294.

Wang, L., Yang, X., Ren, Z., Hu, X., Wang, X. 2015. Alleviation of photosynthetic inhibition in copperstressed tomatoes through rebalance of ion content by exogenous nitric oxide. Turkish Journal of Botany 39(1): 10-22.

Wen, D., Gong, B., Sun, S., Liu, S., Wang, X., Ewi, M., Yang, F., Li, Y., Shi, Q. 2016. Promoting roles of melatonin in adventitious root development of Solanum lycopersicum L. by regulating auxin and nitric oxide signaling. Frontiers in Plant Science, doi: 10.3389/fpls.2016.00718.

Young, J. 1991. The photoprotective role of carotenoids in higher plants. Physiologia Plantarum 83(4): 702-708.

Zanotti, R.F., Lopes, J.C., Motta, L.B., Freitas, A.R., Mengarda, L.H.G. 2013. Tolerance induction to saline stress in papaya seeds treated with potassium nitrate and sildenafil citrate. Ciências Agrárias 34(6): 3669-3674.

Zhang, L.P., Mehta, S.K., Liu, Z.P., Yang, Z.M. 2008. Copper-induced proline synthesis is associated with nitric oxide generation in Chlamydomonas reinhardtii. Plant Cell and Physiology 49(3): 411419. 
Zhang, Y.K., Cui, X.M., Yang, S.X, Chen, X.L. 2010. Effects of exogenous nitric oxide on active oxygen metabolism and photosynthetic characteristics of tomato seedlings under cadmium stress. Chinese Journal of Applied Ecology 21 (6): 1432-1438.

Zheng, C., Jiang, D., Liu, F., Dai, T., Liu, W., Jing, Q., Cao, W. 2009. Exogenous nitric oxide improves seed germination in wheat against mitochondrial oxidative damage induced by high salinity. Environmental and Experimental Botany 67: 222227.

Zimmer-Prados, L. M., Moreira, A.S.F.P., Magalhães, J.R., França, M.G.C. 2014. Nitric oxide increases tolerance responses to moderate water deficit in leaves of Phaseolus vulgaris and Vigna unguiculata bean species. Physiology and Molecular Biology of Plants 20(3): 295-301. 